\title{
Study of the mechanical and chemical properties of potassium manganese phosphate glasses
}

\author{
W. Ahmina ${ }^{1}$, M. El Moudane ${ }^{2}$, M. Zriouil ${ }^{1}$, M. Cherraj ${ }^{3}$ and M. Taibi ${ }^{4}$ \\ ${ }^{1}$ Université Mohammed V de Rabat, Faculté des Sciences, Laboratoire de Chimie du Solide Appliquée, Rabat, \\ Morocco. \\ ${ }^{2}$ Université Mohammed V de Rabat, Faculté des Sciences, Laboratoire des Matériaux, Nanotechnologies et \\ Environnement, Rabat, Morocco. \\ ${ }^{3}$ Université Mohammed V de Rabat, Faculté des Sciences, LMM, dep of physics, Rabat, Morocco. \\ ${ }^{4}$ Université Mohammed V de Rabat, Ecole Normale, Supérieure Takadoum, Laboratoire de Physico-Chimie des \\ Matériaux associé à l'AUF (LAF 502), Rabat, Morocco.
}

\begin{abstract}
Homogeneous phosphate glasses having the general formula $20 \mathrm{~K}_{2} \mathrm{O}-\mathrm{xMnO}-(80-\mathrm{x}) \mathrm{P}_{2} \mathrm{O}_{5}$ were synthesized using a melt-quenching method. The amorphous nature of the samples was asserted by $\mathrm{X}$-ray diffraction. The glasses are studied in order to evaluate the influence of $\mathrm{MnO}$ addition on the chemical and mechanical properties, such as, dissolution rate, average compressive strength (Rc), Young's modulus $(E)$ and limit strain $\left(\varepsilon_{\text {lim }}\right)$. Some studies show that the addition of MnO significantly reduces the degradation rate $\left(D_{R}\right)$ of soluble phosphate glasses and enhanced chemical stability of both alkali-resistance and acid-resistance. $\mathrm{MnO}$ interfere with the chemical structure of the glass, and consequently improve their mechanical properties. Indeed, the mechanical measurements showed that the glass structure was modified by the addition of $\mathrm{MnO}$ oxide, becoming more rigid, and as a result, increasing the compressive strength (Rc), Young's modulus (E). These new materials could be an important opportunity for applications in the fields of building, construction, civil engineering, etc...
\end{abstract}

Keywords: Phosphate glasses, mechanical properties, chemical durability, compressive strength, elastic modulus, strain limit.

\section{Introduction}

Nowadays, the study of the phosphate glasses represents a special part in the large field of material science because of their applications in the different domains [1-2]. The scientific and technological applications of glasses have encouraged researchers to custom-build the novel glasses for the industry. Glasses are receiving considerable attention due to their unique physical properties like hardness, good strength, transparency, excellent corrosion resistance and high chemical stability [3-5]. These properties of glasses to a large extent are controlled by the composition, structure and nature of the bonds of the glasses formed. Phosphate based glasses have several advantages such as bioactivity; they are degradable and non-toxic and have been used as soluble inhibitors and conversion coating materials [6-8]. However, those glasses present poor mechanical and chemical durability properties when compared to silica based glasses. One approach to increasing these properties is to add various oxides to phosphate glasses, such as $\mathrm{PbO}, \mathrm{MgO}$, and $\mathrm{TiO}_{2}$, and $\mathrm{MnO}$, etc. These oxides lead to the formation of Pb-O-P, Mg-O-P, Ti-O-P and Mn-O-P bonds which replace the easily hydrolysable P-P-P bonds and improve dramatically the chemical durability of the modified phosphate glasses [9-13]. Similarly, the properties of these glasses in terms of mechanical, structural, and electrical properties can be also improved by adding some oxides cited 
above. The presence of $\mathrm{P}-\mathrm{O}-\mathrm{Mn}$ bands in higher concentration makes the glass more hydration resistant. The addition of metal oxides to the glass leads to a depolymerisation of the network, with the breaking of $\mathrm{P}-\mathrm{O}-\mathrm{P}$ linkages and the creation of non-bridging. Mechanical strength is a crucial factor for structural application of a material. Although all the characters of applied force, temperature, shape, and surface defects significantly influence the strength of a glass product, the mechanical properties of a glass are basically determined by its elastic module values (e.g., bulk, shear, and Young's modulus). To the best of our knowledge, there is no work related to the effect of metallic oxides addition on the mechanical and chemical and properties of a $\mathrm{K}$ containing phosphate glass. The aim of this work was to investigate the effect of $\mathrm{MnO}$ addition on the dissolution rates and mechanical properties of potassium phosphates glasses, such as degradation rate $\left(D_{R}\right)$, compressive strength $(R c)$, Young's modulus $(\mathrm{E})$, and limit strain $\left(\varepsilon_{\mathrm{lim}}\right)$.

\section{Materials and methods}

The glass samples were prepared from reagent grades of $\mathrm{K}_{2} \mathrm{CO}_{3}, \mathrm{MnCO}_{3}$ and $\mathrm{NH}_{4} \mathrm{H}_{2} \mathrm{PO}_{4}$, mixed according to the molar composition. Were prepared by mixing proportionally weighed raw materials and melted at $1100^{\circ} \mathrm{C}$ for $1 \mathrm{~h}$. Details of the procedure adopted in the preparation of these glasses have been described in our earlier work [13].

$\mathrm{X}$-ray diffraction patterns were recorded at room temperature with a Simens D5000 diffractometer using $\mathrm{CuK}$ radiation.

For the chemical durability analysis, samples they were then immersed into a beaker filled with $50 \mathrm{~mL}$ of different medium at $25^{\circ} \mathrm{C}$ for 6,12 and 24 hours. The dissolution rate (DR) was determined from the weight loss during the aqueous treatment at $25^{\circ} \mathrm{C}$. The dissolution rate (DR) was calculated as:

$$
D R=\frac{\Delta \mathrm{w}}{\mathrm{S} . \mathrm{t}}
$$

Where $\Delta \mathrm{w}$ is the weight loss $(\mathrm{g}), \mathrm{S}$ is the sample area $\left(\mathrm{cm}^{2}\right)$ before the dissolution test and $\mathrm{t}$ is the dissolution time ( $\mathrm{min}$ ).

Compression testing of four glasses (V1), (V2), (V3) and (V4) are also performed on cylindrical specimens of dimensions $\mathrm{h}=5 \mathrm{~mm}$ and diameter $=8 \mathrm{~mm}$. These specimens are made by a static compaction with an effort of 5MPa associated with the different dosages of manganese oxide 15 , 20, 25 and $30 \mathrm{~mol} \%$ (Figure 1).

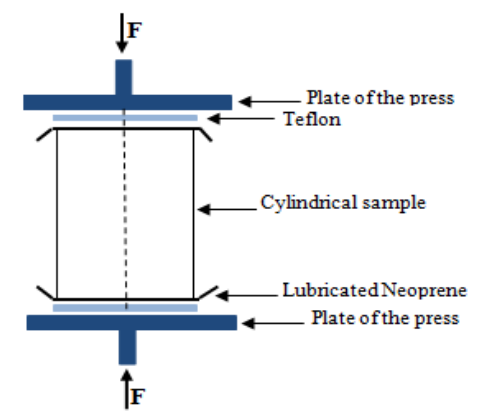

Fig.1. Experimental material of compression test

Glass shows an almost perfect brittle-elastic behavior at temperatures lower than the transformation point. The strain is proportional to the stress according to Hooke's law. If the ends of a rod are exposed to a stress $\sigma$, its relative elongation is given by:

$$
\sigma=E . \varepsilon
$$

Where:

$$
\begin{aligned}
& \sigma: \text { is stress }[\mathrm{MPa}] \\
& \mathrm{E}: \text { modulus of elasticity }[\mathrm{MPa}] \\
& \varepsilon: \text { strain }
\end{aligned}
$$

\section{Glass-forming region}

The glass forming region is shown in triaxial $\mathrm{K}_{2} \mathrm{O}$, $\mathrm{MnO}, \mathrm{P}_{2} \mathrm{O}_{5}$ diagram by area enclosed by the solid line in fig.2.

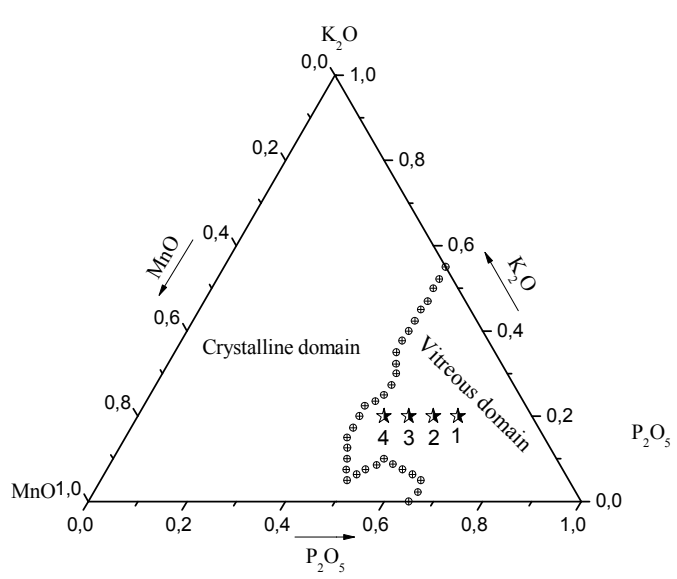

Fig.2. The glass-forming region in the systemK $\mathrm{K}_{2} \mathrm{O}-\mathrm{MnO}-\mathrm{P}_{2} \mathrm{O}_{5}$ at $1100{ }^{\circ} \mathrm{C}$ [12] (see Table

1 for the correspondence between the batch numbers and chemical composition) 
Table 1. Composition (mol \%), density $\rho\left(\mathrm{g} . \mathrm{cm}^{-3}\right)$ of the studied specimens.

\begin{tabular}{|c|c|c|c|c|}
\hline Glass no. & $\mathrm{K}_{2} \mathrm{O}$ & $\mathrm{MnO}$ & $\mathrm{P}_{2} \mathrm{O}_{5}$ & $\rho$ \\
\hline $\mathrm{V} 1$ & 20 & 15 & 65 & 2.64 \\
\hline $\mathrm{V} 2$ & 20 & 20 & 60 & 2.72 \\
\hline $\mathrm{V} 3$ & 20 & 25 & 55 & 2.81 \\
\hline $\mathrm{V} 4$ & 20 & 30 & 50 & 2.89 \\
\hline
\end{tabular}

\section{3 results and discussion}

\subsection{X-ray diffraction}

As shown in Fig. 3, the X-ray diffraction patterns for all the studied compositions, confirms their amorphous nature, since there is no sharp peak observed in the diffraction pattern.

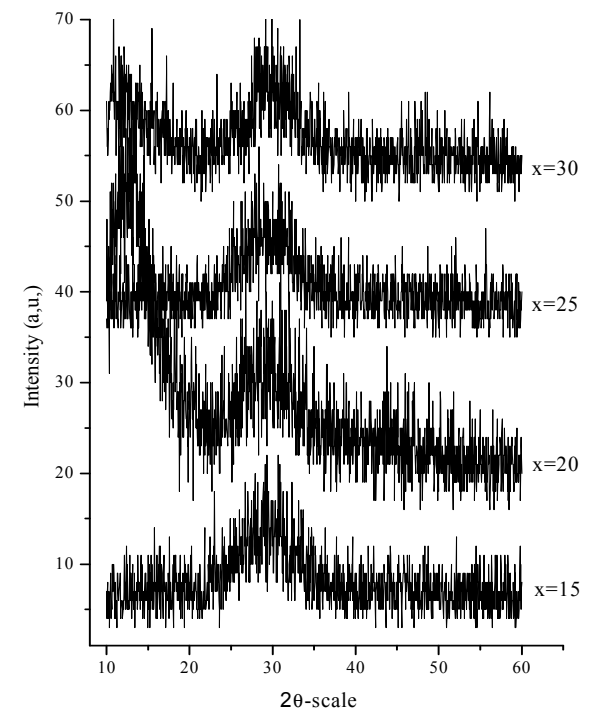

Fig.3. X-ray powder diffraction patterns of the $\mathrm{K}_{2} \mathrm{O}$ $\mathrm{MnO}-\mathrm{P}_{2} \mathrm{O}_{5}$ system.

\subsection{Chemical durability}

The dissolution rates $D_{R}$ of the potassium manganese phosphate glasses, measured from their weight loss in distilled water at $25^{\circ} \mathrm{C}$, are given in Table 2 and fig. 3.

All the leaching experiments were carried out at $\mathrm{pH}$ $=4,6$ and 11. The leaching experiments at ambient temperature were carried out on all glasses from V1 to V4 at all leaching times of $6 \mathrm{~h}, 12 \mathrm{~h}$ and 24 hours, with leaching solutions of $\mathrm{HCl}(\mathrm{pH}=4)$, distilled water $(\mathrm{pH}=6)$, and $\mathrm{NH}_{3}(\mathrm{pH}=11)$.

Table 2 summarizes the values of the dissolution rates DR changes for all of these leaching experiments. In a general manner, all the glasses studied exhibit similar behavior as a function of the $\mathrm{pH}$ and whatever the time of alteration. The dissolution rates DR of the leachate decreases in an initially neutral and basic medium whereas it increases in an initially acidic medium.

\subsubsection{Variation of the dissolution rates (DR)}

Fig. 4 shows the effect of $\mathrm{MnO}$ concentration on the dissolution rate at different times of $20 \mathrm{~K}_{2} \mathrm{O}$ $\mathrm{xMnO}-(80-\mathrm{x}) \mathrm{P}_{2} \mathrm{O}_{5}(\mathrm{x}=15,20,25$ and 30$)$ glasses immersed in distilled water at $25^{\circ} \mathrm{C}$. The dissolution Table 2. Dissolution rate DR $\left(\mathrm{g} . \mathrm{cm}^{-3} \cdot \mathrm{min}^{-1}\right)$ of $20 \mathrm{~K}_{2} \mathrm{O}$ $x \mathrm{MnO}-(80-x) \mathrm{P}_{2} \mathrm{O}_{5}$ glasses in three different middle $(\mathrm{pH}=$ 4,6 and 11 ) at $25^{\circ} \mathrm{C}$ for 24 hours.

\begin{tabular}{|c|c|c|c|c|}
\hline \multirow{3}{*}{$\begin{array}{c}\text { Initial } \\
\mathrm{pH}\end{array}$} & $\begin{array}{c}\text { Composition } \\
(x)\end{array}$ & \multicolumn{3}{|c|}{$\begin{array}{c}\text { DR values after an immersion } \\
\text { time of } 6,12 \text { and } 24 \text { hours }\end{array}$} \\
\cline { 2 - 5 } & & 6 & 12 & 24 \\
\hline \multirow{4}{*}{4} & 15 & $3,89.10^{-6}$ & $4,26.10^{-6}$ & $3,31.10^{-6}$ \\
\cline { 2 - 5 } & 20 & $6,91.10^{-6}$ & $6,45.10^{-6}$ & $5,49.10^{-6}$ \\
\cline { 2 - 5 } & 25 & $7,76.10^{-6}$ & $7,24.10^{-6}$ & $6,30.10^{-6}$ \\
\cline { 2 - 5 } & 30 & $8,51.10^{-6}$ & $7,26.10^{-6}$ & $6,60.10^{-6}$ \\
\hline \multirow{4}{*}{6} & 15 & $1,69.10^{-5}$ & $1,28.10^{-5}$ & $1,23.10^{-5}$ \\
\cline { 2 - 5 } & 20 & $1,54.10^{-5}$ & $1,20.10^{-5}$ & $9,54.10^{-6}$ \\
\cline { 2 - 5 } & 25 & $8,91.10^{-6}$ & $7,24.10^{-6}$ & $6,30.10^{-6}$ \\
\cline { 2 - 5 } & 30 & $4,17.10^{-6}$ & $3,39.10^{-6}$ & $2,29.10^{-6}$ \\
\hline \multirow{4}{*}{11} & 15 & $7,08.10^{-6}$ & $6,92.10^{-6}$ & $6,76.10^{-6}$ \\
\cline { 2 - 5 } & 20 & $5,50.10^{-6}$ & $5,24.10^{-6}$ & $4,78.10^{-6}$ \\
\cline { 2 - 5 } & 25 & $4,78.10^{-6}$ & $3,98.10^{-6}$ & $3,80.10^{-6}$ \\
\cline { 2 - 5 } & 30 & $4,46.10^{-6}$ & $3,31.10^{-6}$ & $2,75.10^{-9}$ \\
\hline
\end{tabular}

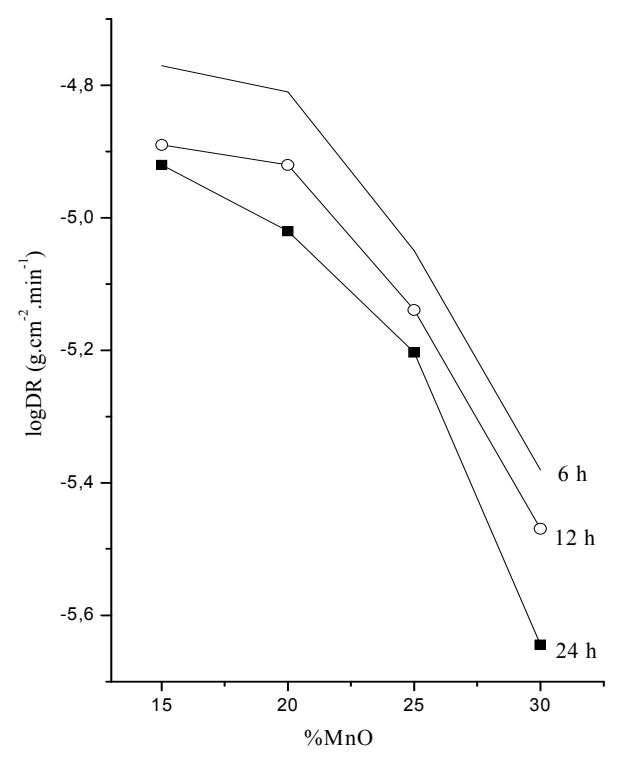

Fig.4. Composition dependence of dissolution rates (DR) for $20 \mathrm{~K}_{2} \mathrm{O}-\mathrm{xMnO}-(80-\mathrm{x}) \mathrm{P}_{2} \mathrm{O}_{5}$ glasses after immersion in distilled water at $25{ }^{\circ} \mathrm{C}$ for $6 \mathrm{~h}, 12 \mathrm{~h}$ and 24 hours. 
rate decreases slightly between 15 and $20 \mathrm{~mol} \%$ $\mathrm{MnO}$. For $\mathrm{MnO}$ additions $>20 \mathrm{~mol} \%$, the dissolution rate decreases rapidly as $\mathrm{MnO}$ concentration increases.

The increasing addition of $\mathrm{MnO}$ gives a decrease in solubility. Therefore, in our case we assumed that the higher dissolution rate for less than $20 \% \mathrm{MnO}$ corresponds to the release of metaphosphate chains into the solution. As it was discussed in our previous works $[12,13]$ from IR and Raman spectra, the addition of less than $20 \mathrm{~mol} \% \mathrm{MnO}$ shows that $\mathrm{MnO}$ has a smaller effect on the glass structure with infinite long chains of $\mathrm{PO}_{4}$ tetrahedra. When increasing $\mathrm{MnO}$ concentration, the metaphosphate chains are broken into smaller groups of short chain phosphates such as $\mathrm{P}_{4} \mathrm{O}_{13}{ }^{6-}, \mathrm{P}_{3} \mathrm{O}_{10}{ }^{5-}$ and $\mathrm{P}_{2} \mathrm{O}_{7}{ }^{4-}$, which are linked to manganese through $\mathrm{P}-\mathrm{O}-\mathrm{Mn}$ bonds. The formation of $\mathrm{P}-\mathrm{O}-\mathrm{Mn}$ bonds increases the cross-link between the phosphate chains and leads to enhanced chemical durability, in accordance with the increase of $\mathrm{Tg}$ [12-13]. These variations can be explained by the effect of the cation substitution on the reticulation of the glasses. The $\mathrm{MnO}$ addition causes a shrinking of the phosphate network and creates a more entangled and reticulated metaphosphate chains [14]. In addition, the $\mathrm{P}-\mathrm{O}-\mathrm{K}$ bonds are more sensitive to the hydration process compared to P-O-Mn bonds. These combined effects make the high $\mathrm{MnO}$ glasses composition more resistant toward water attack and delay its diffusion into the glasses [15].

\subsubsection{Variation of the $\mathrm{pH}$}

The table 3 summarizes the $\mathrm{pH}$ vales as a function of the time of immersion in three different middles.

Table 3. Composition dependence of $\mathrm{pH}$ of $20 \mathrm{~K}_{2} \mathrm{O}-x$ $\mathrm{MnO}-(80-x) \mathrm{P}_{2} \mathrm{O}_{5}$ glasses in three different middle $(\mathrm{pH}=$ $4,6$ and 11$)$ at $25^{\circ} \mathrm{C}$ for 24 hours.

\begin{tabular}{|c|c|c|c|c|}
\hline \multirow{3}{*}{$\begin{array}{c}\text { Initial } \\
\mathrm{pH}\end{array}$} & \multirow{2}{*}{$\begin{array}{c}\text { Composition } \\
(\text { x mol \%) }\end{array}$} & \multicolumn{3}{|c|}{$\begin{array}{c}\mathrm{pH} \text { values after an immersion } \\
\text { time of } 6,12 \text { and } 24 \text { hours }\end{array}$} \\
\cline { 3 - 5 } & & 6 & 12 & 24 \\
\hline \multirow{4}{*}{4} & 15 & 6.99 & 7.13 & 7.17 \\
\cline { 2 - 5 } & 20 & 7.18 & 7.22 & 7.32 \\
\cline { 2 - 5 } & 25 & 7.82 & 7.93 & 7.98 \\
\cline { 2 - 5 } & 30 & 8.28 & 8.42 & 8.78 \\
\hline \multirow{4}{*}{6} & 15 & 8.40 & 8.75 & 9.22 \\
\cline { 2 - 5 } & 20 & 8.11 & 8.53 & 8.70 \\
\cline { 2 - 5 } & 25 & 7.81 & 8.02 & 8.26 \\
\hline \multirow{4}{*}{11} & 30 & 7.78 & 7.96 & 8.07 \\
\cline { 2 - 5 } & 15 & 10.55 & 10.37 & 10.17 \\
\cline { 2 - 5 } & 20 & 10.58 & 10.45 & 10.26 \\
\cline { 2 - 5 } & 25 & 10.61 & 10.48 & 10.32 \\
\hline
\end{tabular}

The figure 5 shows the evolution of the $\mathrm{pH}$ as a function of the $\mathrm{MnO}$ content. It is noticed that the $\mathrm{pH}$ of the solution decreases continuously during a times being less than 12 hours, and beyond this value it slows down progressively.

This figure shows that from an initial value of 6 for distilled water, increases continuously with the immersion time to reach a maximum value of 9.22. A similar behavior was observed for the medium of $\mathrm{pH}=4$.

The increase in the $\mathrm{pH}$ of the leaching solutions is related to the inter-diffusion of the hydronium $\left(\mathrm{H}^{+}\right)$ ions of the solution and the potassium $\left(\mathrm{K}^{+}\right)$ions of the glass. Thus, the dissolution of potassium manganese metaphosphate glasses can be directly related to the concentration of non-bridging oxygen (NBOs) in these glasses. Indeed, when a water molecule diffuses towards the vitreous network, it becomes immobile in the neighborhoods of nonbridging oxygen (NBOs). The formation of the groups $\left(\mathrm{P}-\mathrm{O}-\mathrm{H}^{+}\right)$is made simultaneously with the diffusion of the $\mathrm{K}^{+}$ion with its hydroxyl $\left(\mathrm{OH}^{-}\right)$coion at the glass/solution interface [16].

This process can be schematized as follows:

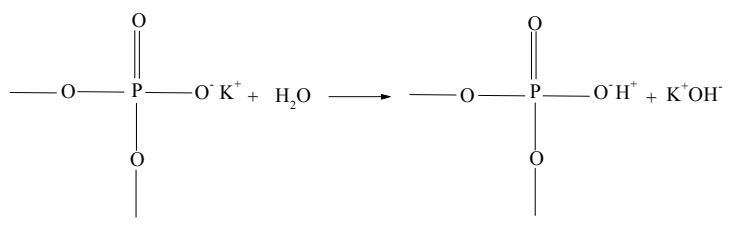

Table 4. Experimental results means the mechanical characteristics of the studied glasses

\begin{tabular}{|l|l|l|l|}
\cline { 2 - 4 } \multicolumn{1}{c|}{} & $\mathrm{E}(\mathrm{MPa})$ & $\mathrm{Rc}(\mathrm{MPa})$ & $\varepsilon_{\lim }(\%)$ \\
\hline V1 & 417 & 31.73 & 28.17 \\
\hline V2 & 2193 & 37.45 & 19.64 \\
\hline V3 & 2474 & 42.64 & 17.73 \\
\hline V4 & 2759 & 54.91 & 15.34 \\
\hline
\end{tabular}




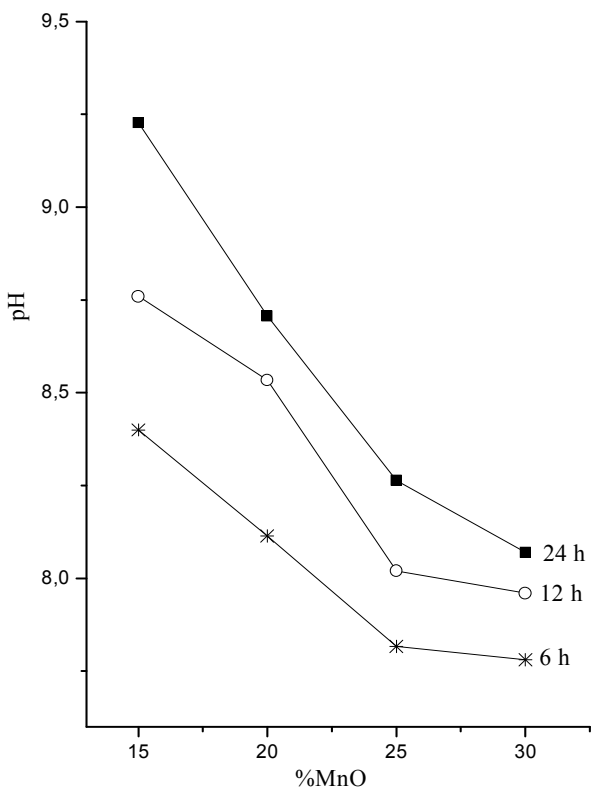

Fig.5. Composition dependence of $\mathrm{pH}$ for $20 \mathrm{~K}_{2} \mathrm{O}$ $\mathrm{xMnO}-(80-\mathrm{x}) \mathrm{P}_{2} \mathrm{O}_{5}$ glasses after immersion in distilled water at $25^{\circ} \mathrm{C}$ for $6 \mathrm{~h}, 12 \mathrm{~h}$ and 24 hours.

The basification of the $\mathrm{pH}=4$ and $\mathrm{pH}=6$ solutions can be attributed to the alkali extraction by ion exchange mechanisms between the protons of the solution and the network modifying elements, this exchange process is responsible for the increase of $\mathrm{pH}$ due to the increase of residual $\mathrm{OH}^{-}$ions in the solution.

For solutions initially basic $\mathrm{pH}=11$, the evolution of $\mathrm{pH}$ over time is less meaningful than for solutions of $\mathrm{pH}=4$ and 6 for all glasses. Indeed, we notice a drop in $\mathrm{pH}$. It evolves with time and reaches its minimum value at 24 hours certainly due to a consumption $\mathrm{OH}^{-}$ion.

\subsection{Mechanical properties}

\subsubsection{Effect of the chemical constituents of the glass on the mechanical behavior of the vitreous material}

The experimental results of the average compressive strength (Rc), the Young modulus (E) and the limit strain $\left(\varepsilon_{\text {lim }}\right)$ of four glasses, associated with different dosages of manganese oxide, are summarized in Table 4.

Table 4. Experimental results means the mechanical characteristics of the studied glasses
Figs. 6 and 7 give the evolution of the compressive strength, the Young's modulus and the limit strain of four glasses (V1), (V2), (V3) and (V4).

As can be seen from Fig. 6, the Young's modulus values increase with $\mathrm{MnO}$ content. The influence of the manganese oxide content on the strength characteristics of glasses is illustrated by the data presented in Table 4 and Fig. 6. The glasses contains over $20 \mathrm{~mol} \%$ manganese oxide, and present a greater rigidity than the glass (V1).The rigidity is generally dependent upon the bond strength and cross-link density. The increase in elastic modulus with an increase in $\mathrm{MnO}$ content is attributed to increasing in the cross-link density and rigidity of glass. In addition, $\mathrm{MnO}$ enters into the glass network in a position which create a crosslinking between $\mathrm{Mn}^{2+}$ ions and the phosphate tetrahedral (Mn-O-P instead of $\mathrm{P}-\mathrm{O}-\mathrm{P}$ ). Thus, the enhancement of the structure with addition of $\mathrm{MnO}$ beyond $30 \mathrm{~mol} \%$ results in the increase in modulus, as noticed in Figs. 6-7, and Table 4. That $\mathrm{MnO}$ has the ability to enter into the vitreous arrangements.

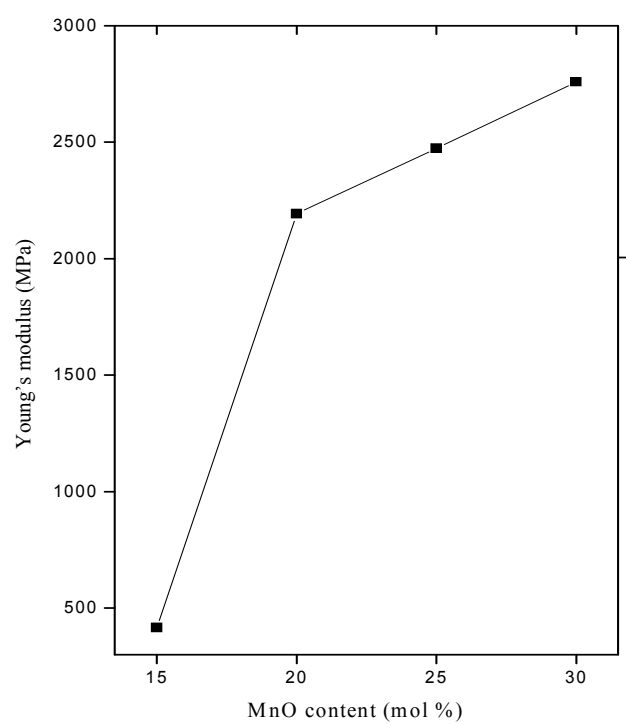

Fig. 6.Variation of Elastic modulus versus $\mathrm{MnO}$ content $\mathrm{mol} \%$. 


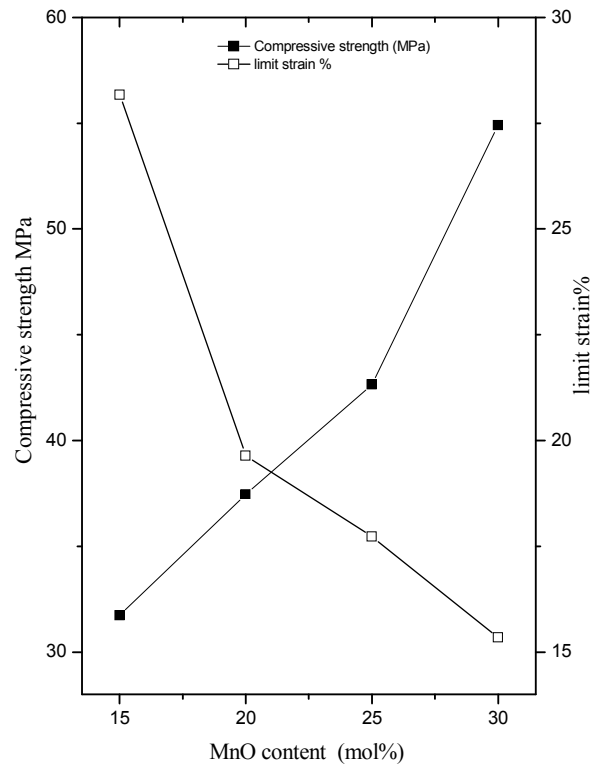

Fig.7. Variation of compressive strength and limit strain versus $\mathrm{MnO}$ content in $\mathrm{mol} \%$.

and thus, creates a stronger Mn-O-P linkage and increases the $\mathrm{O} / \mathrm{P}$ ratios in the network are causes depolymerisation in the phosphate network. In consequently, the glass network becomes compact and thereby increases elastic modulus as observed in Figs. 6 and 7. This result is in agreement with our recently studies [12,13]. The addition of manganese oxide to the glass increases the density of glasses which ranged from $2.64 \mathrm{~g} / \mathrm{cm}^{3}$ for (V1) to $2.89 \mathrm{~g} / \mathrm{cm}^{3}$ for (V4) (Table 1). The glass transition temperature also increased with the addition of $\mathrm{MnO}$ to the $20 \mathrm{~K}_{2} \mathrm{O}-\mathrm{xMnO}-(80-\mathrm{x}) \mathrm{P}_{2} \mathrm{O}_{5}$ glasses. Results presented in Tables 1 and 4 , and Figures 6 and 7 show that the density and the compressive strength increase with increasing $\mathrm{MnO}$ in the glass, stiffens the material and reduces its ability to deform as showed in figure 7 .

. This is due to the presence of $\mathrm{MnO}$ oxide which provides more density and more strength than $\mathrm{K}_{2} \mathrm{O}$. This indicates that replacement of $\mathrm{K}^{+}$ion by $\mathrm{Mn}^{2+}$ ion increase the density as well as compressive strength of the of glass.

The potassium manganese phosphate network becomes stronger with increasing $\mathrm{MnO}$ content. The improved durability with increased $\mathrm{MnO}$ content is attributed to the easy hydrated P-O-P bonds being replaced by more chemically resistant Mn-O-P bonds. The elastic modulus of the glass samples shows an improvement in their mechanical properties with the increase in the $\mathrm{MnO}$ content.

This increase in strength is believed to be due to the replacement of monovalent potassium ions by divalent manganese ions which increases the crosslink density in the glass structure and makes the glass stronger. The combination of high strength and good chemical durability of the manganese phosphate glasses, along with the fact that they can be prepared at relatively low temperatures, are valuable advantages for potential technological applications. The observed decrease in limit strain can be attributed to the resulted increase in rigidity and the glass network connectivity. Similar results were found by Hsu et al. [17] and by Hand and Tadjiev [18] when studying, respectively $\mathrm{Nb}-\mathrm{Sr}$ phosphate glasses and Mg-silicate glasses.

\section{Conclusions}

In this work, we presented the preliminary results obtained for $20 \mathrm{~K}_{2} \mathrm{O}-x \mathrm{MnO}-(80-x) \mathrm{P}_{2} \mathrm{O}_{5} \quad(15 \leq x \leq 30)$ glasses investigated by XRD and chemical durability. It was confirmed that the prepared glasses are amorphous. The improved chemical durability with increasing manganese content is attributed to the easily hydrated P-O-P bond being replaced by more chemically resistant Mn-O-P bond. The mechanical properties of potassium manganese phosphate have been investigated. On increasing the amount of $\mathrm{MnO}$ in the glass samples, density, Young's moduli and compressive strength were found to increase accordingly. The results revealed that chemical durability is in good agreement with the mechanical properties. Glasses containing more than $20 \mathrm{~mol} \%$ of $\mathrm{MnO}$ had excellent chemical resistance, good mechanical strength and rigidity.

\section{References}

1. M.A. El-Ahdal, E.M. Antar, H.H. Mahmoud, F.M. Ezz-Eldin, J. App. Sci. Res. 7 (2011) 1434.

2. R. Suwimon, Sci. Tech.Nuc.Inst., 218041 (2014) 5 .

3. B. C. Sales, L. A. Boatner, Journal of NonCrystalline Solids, vol. 79 (1986).

4. Y. B. Peng and D. E. Day, Glass Technology, 32(1991).

5. N. Aranha, O. L. Alves, L. C. Barbosa, C. L. Cesar, in Proceedings of the 17th International Congress Glass, Beijing, China, 7(1995).

6. I.M. Zin, S.B. Lyon, V.I. Pokhmurskii, Sci. 45 (2003). 
7. A.M. Simoes, J. Torres, R. Picciochi, J.C.S. Fernandes, Acta 54 (2009).

8. K. Ogle, R. Bucheit, Conversion coatings, in: A.J. Bard, M. Stratmann (Eds.), Encyclopedia of the Electrochemistry, 5, Wiley-VCH, Weinheim, (2003).

9. R.O. Omrani, S. Krimi, J.J. Videau, I. Khattech, A. El Jazouli, M. Jemal, J. Non-Cryst. Solids 389 (2014) 66.

10. S.T. Reis, M. Karabulut, D.E. Day, J. NonCryst. Solids 292 (2001) 150.

11. D.S.L.Weiss, R.D. Torres, S. Buchner, S. Blunk, P. Soares, J. Non-Cryst. Solids $\mathbf{3 8 6}$ (2014) 34-38

12. W. Ahmina, M. El Moudane, M. Zriouil, M. Taibi, Phase transitions 89 (11) (2016) 1051.

13. W. Ahmina, M. El Moudane, M. Zriouil, M. Taibi, J. Mater. Environ. Sci. 7(2) (2016) 444.

14. D.S. Brauer, Phosphate glasses, in: J.R. Jones, A.G. Clare (Eds.), Bio-Glasses: $A n$ Introduction, John Wiley \& Sons, Chichester, (2012).

15. B.C. Bunker, G.W. Arnold, J.A. Wilder, J. Non Cryst. Solids 64 (1984).

16. M. Abid, M. Et-tabirou, M. Hafid, Journal of Materials Science \& Surface Engineering, 5(4) (2017)

17. S.M. Hsu, J.J. Wu, S.W. Yung, T.S. Chin, T. Zhang, Y.M. Lee, C.M. Chu, J.Y. Ding, J. NonCryst. Solids 358 (2012) 14.

18. R. J. Hand, D. R. Tadjiev, J. Non-Cryst. Solids 356 (2010) 2417. 